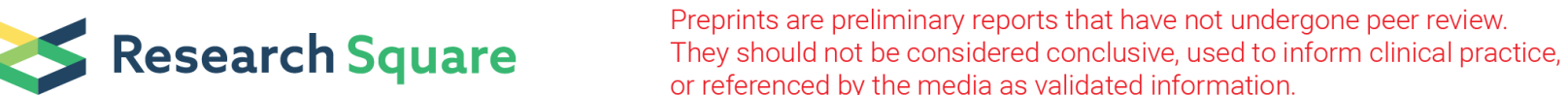

\section{A Clustering Based Image Segmentation Procedure to Automatically Detect Grains in Polycrystalline Materials}

\section{Dženana Alagić ( $\square$ Dzenana.Alagic@k-ai.at)}

KAI: Kompetenzzentrum Automobil- und Industrieelektronik GmbH https://orcid.org/0000-0002-65675223

\section{Jürgen Pilz}

Alpen-Adria Universitat Klagenfurt Fakultat fur Technische Wissenschaften

\section{Research}

Keywords: Microstructure, Grain segmentation, Gaussian Mixture Modeling, Seeded Region Growing, Patch-based clustering

Posted Date: November 23rd, 2020

DOI: https://doi.org/10.21203/rs.3.rs-112115/v1

License: (c) (i) This work is licensed under a Creative Commons Attribution 4.0 International License. Read Full License 


\section{Abstract}

The physical and mechanical properties of a polycrystalline material depend on its microstructure characteristics such as the size and morphology of grains. In practice, different imaging methods are used to visualize the grain structure of such materials. To analyze microstructural changes in case of applied stress and to predict its performance in a given application, the quantitative information about the grain structure must be taken into account. In this work, an effcient and reproducible algorithm, which automatically detects grains in different types of microstructure images, is proposed. Due to the diversity between the analyzed images and a limited number of labeled data, a clustering patch-based approach is followed. The algorithm aims to distinguish between patches in homogeneous grain areas and those lying on grain boundaries through Gaussian Mixture Modeling. The identified groups of grain patches are used to create the seed image for a Seeded Region Growing algorithm, enabling nally a pixelwise image segmentation.

\section{Full Text}

This preprint is available for download as a PDF.

\section{Figures}

\begin{tabular}{|l|}
\hline Image denoising $\rightarrow$ Create grid $\rightarrow$ Feature extraction $\rightarrow$ Patch clustering $\rightarrow$ SRG algorithm \\
\hline
\end{tabular}

\section{Figure 1}

The main steps of the proposed workflow. 


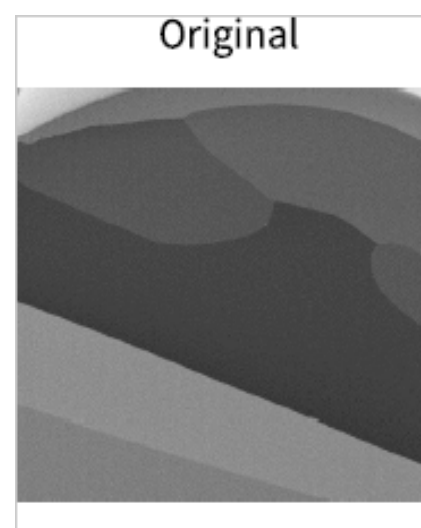

Grid
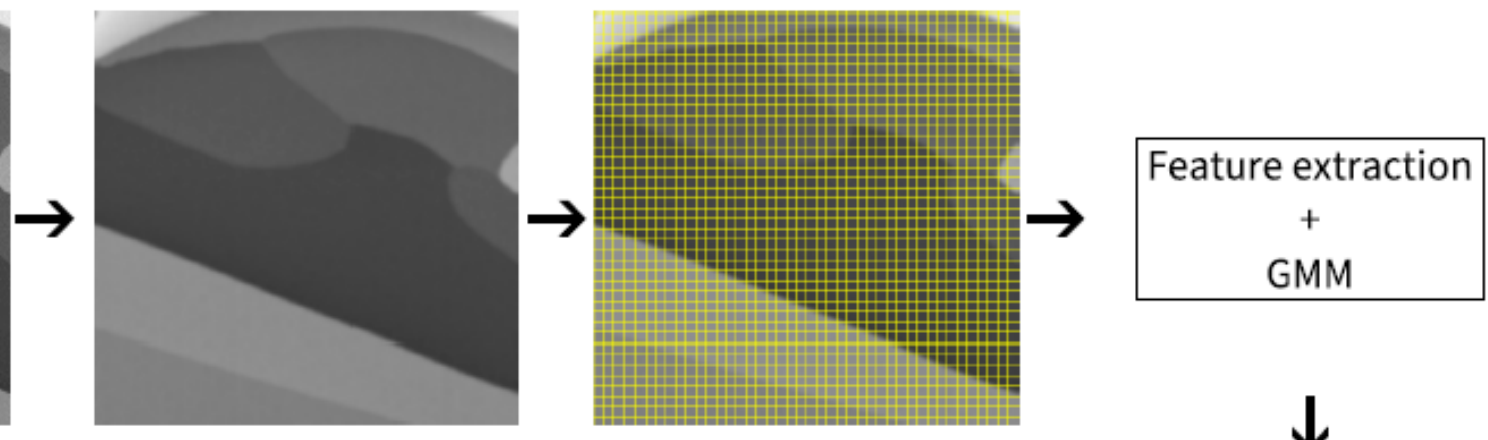

$\downarrow$

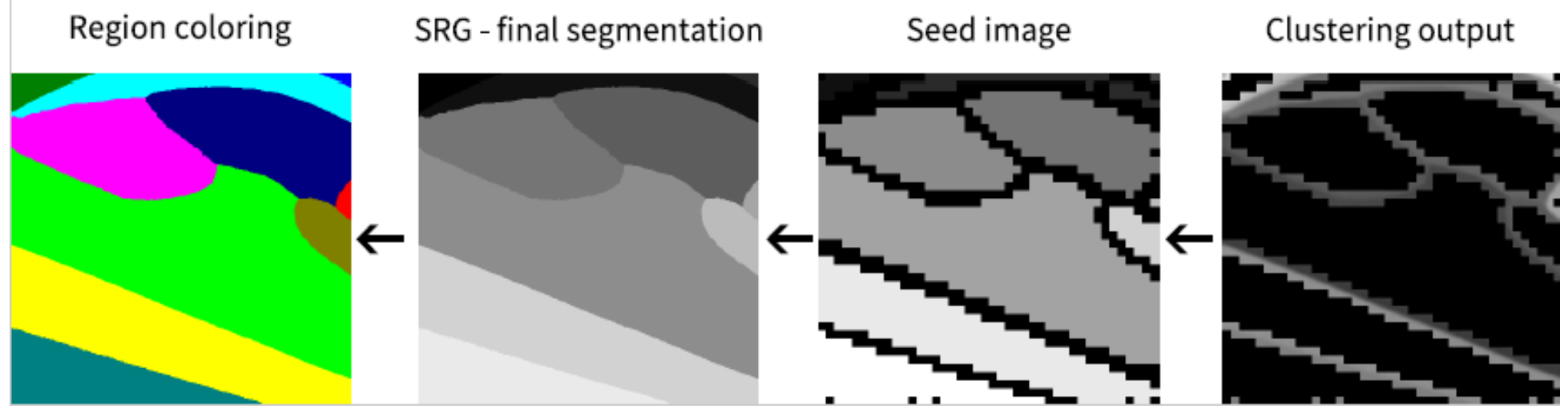

Figure 2

The proposed workflow in details.

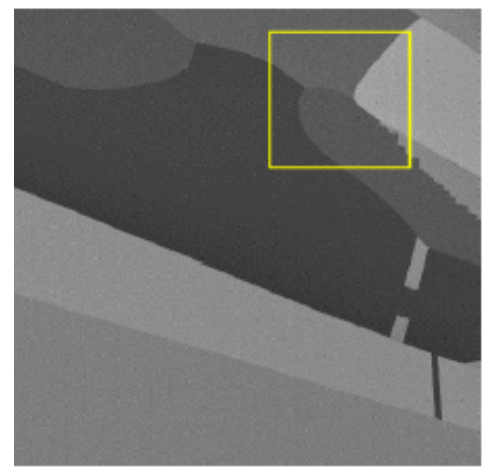

Original
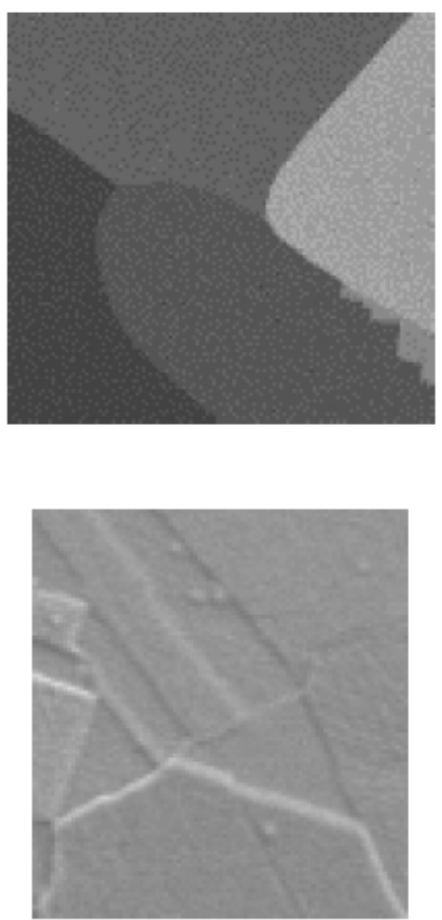

Gaussian Blur (sigma=2)
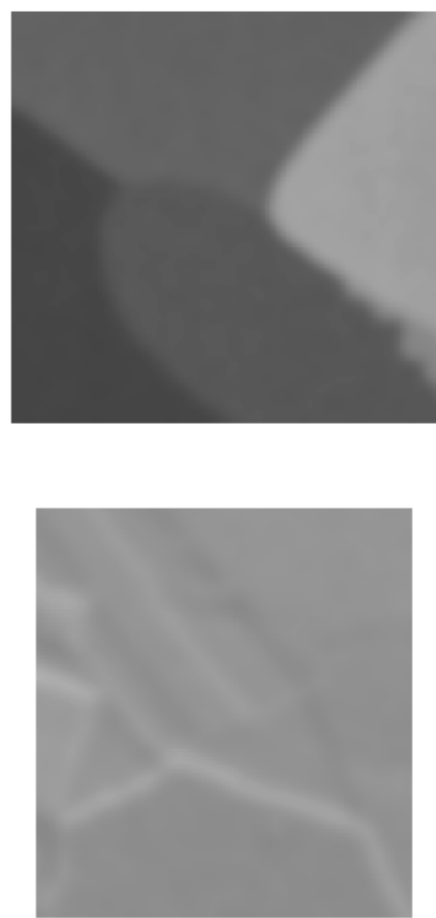

NL-means (sigma=4)
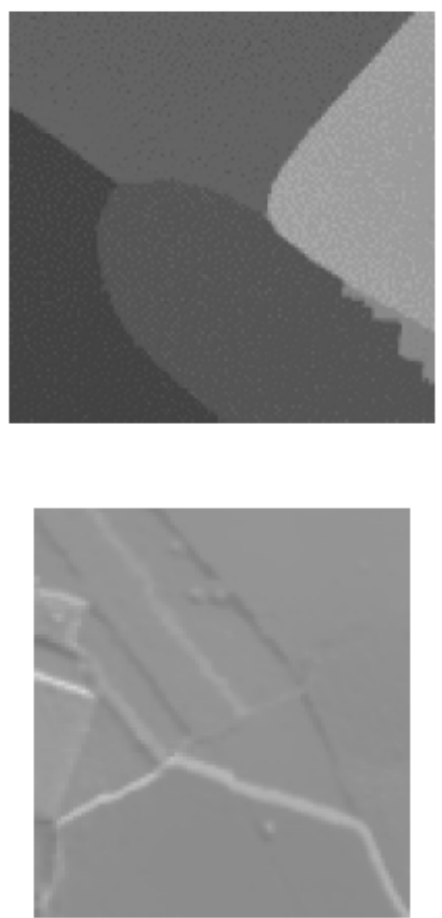

Figure 3 
The effect of different denoising methods.

Original
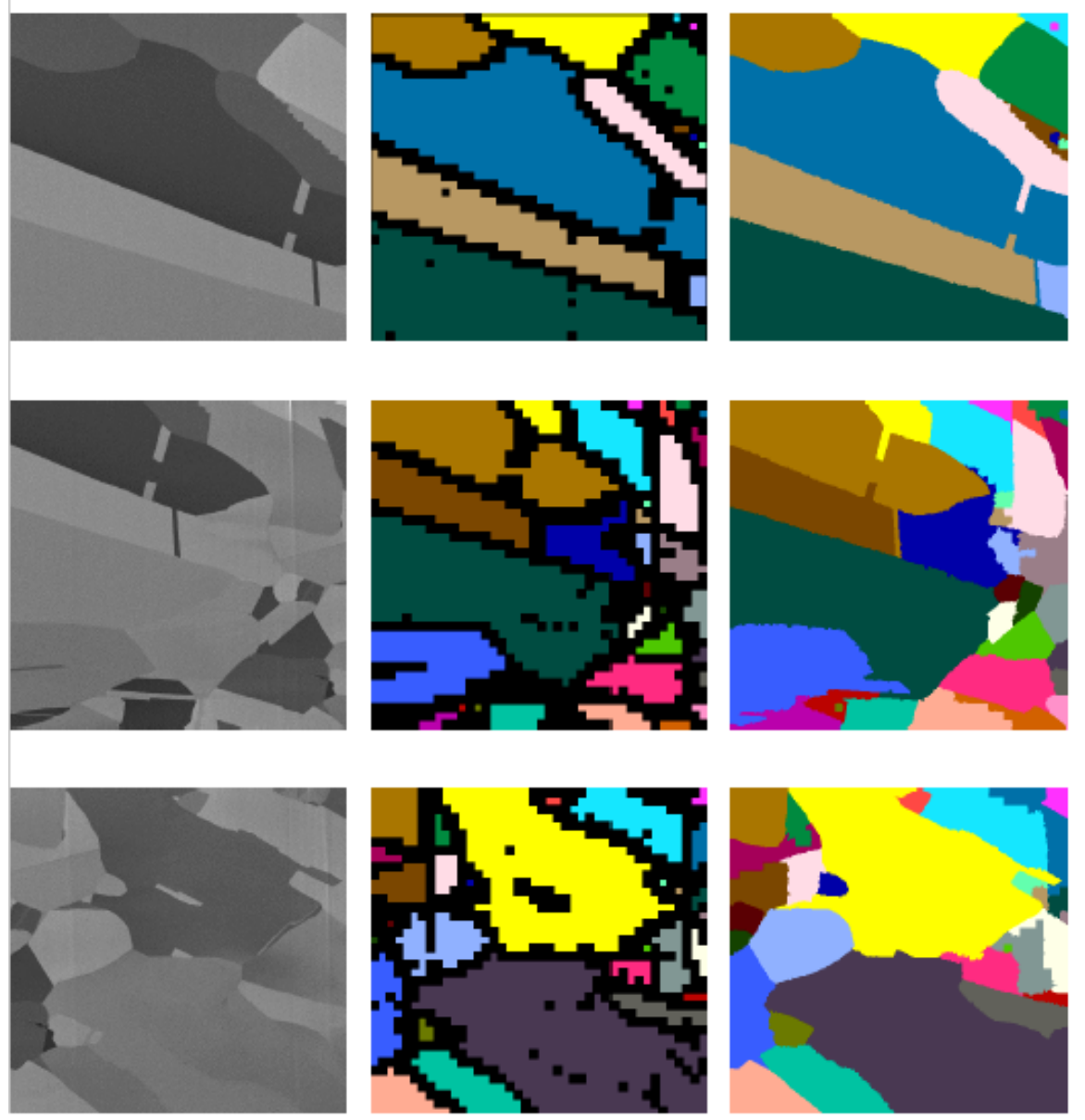

Manual seeds
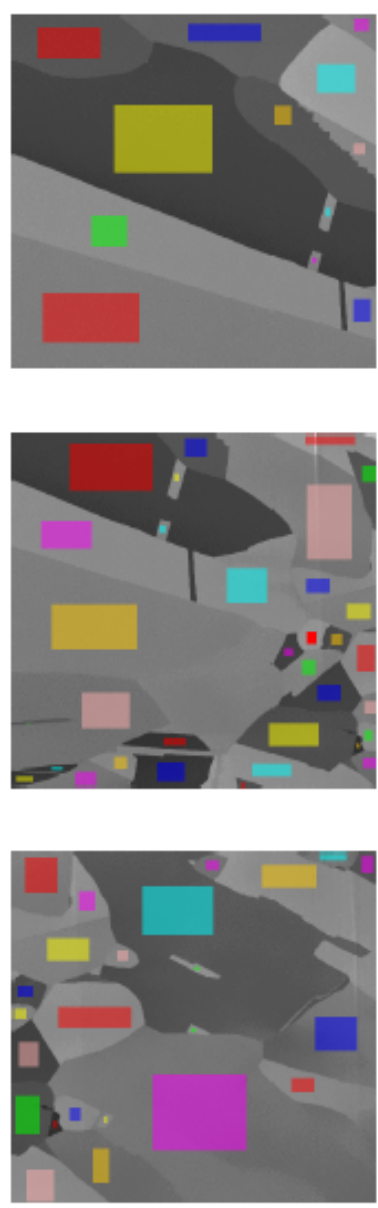

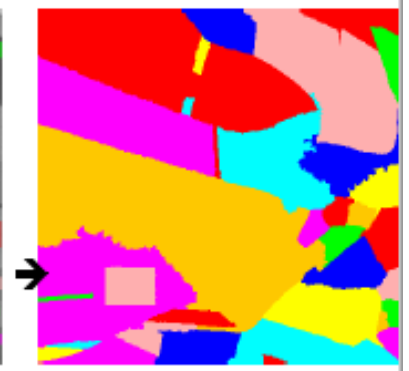

SRG output
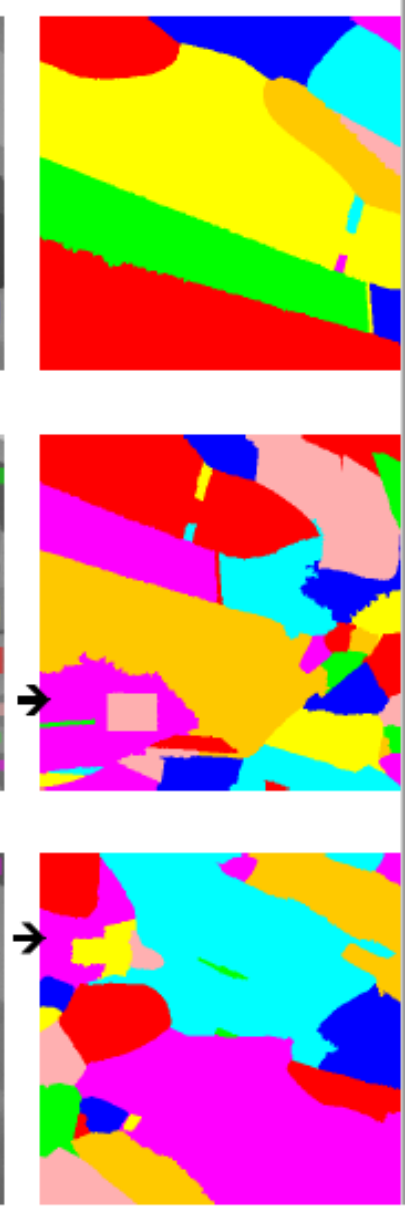

Figure 4

Results for FIB images. 


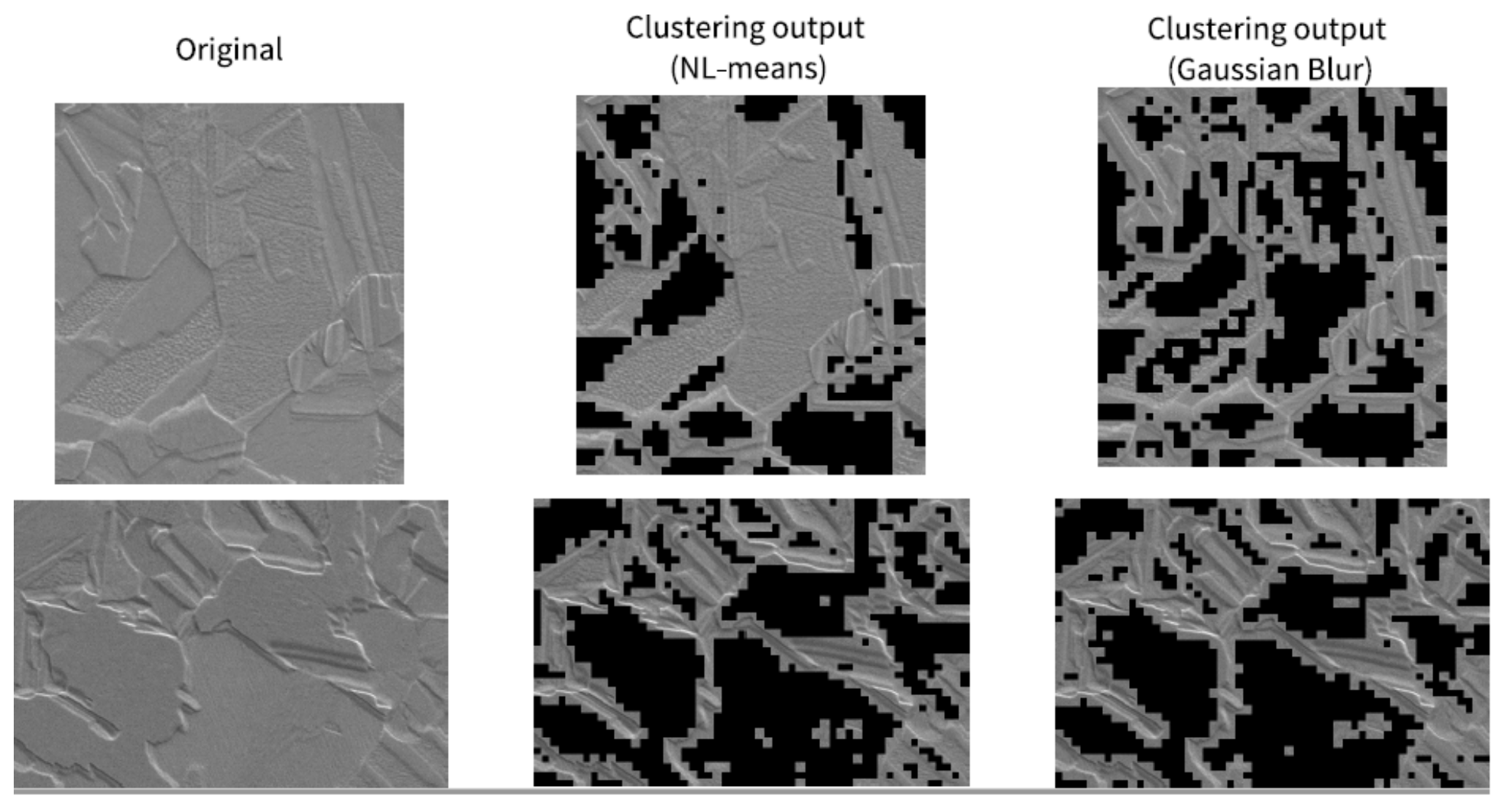

Figure 5

The effect of denoising methods on clustering output. 
Test 01

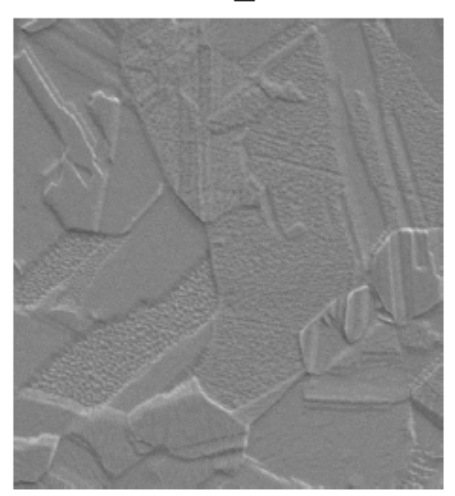

Clustering output (combination)

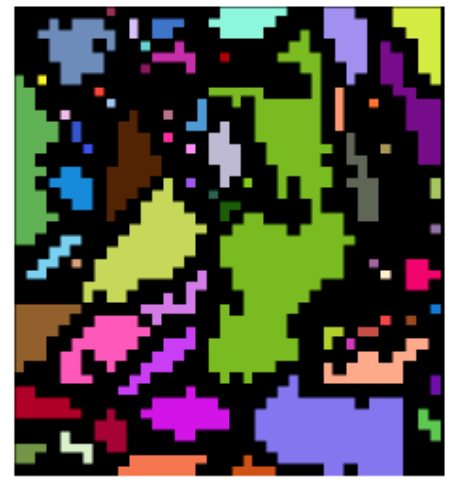

Final segmentation
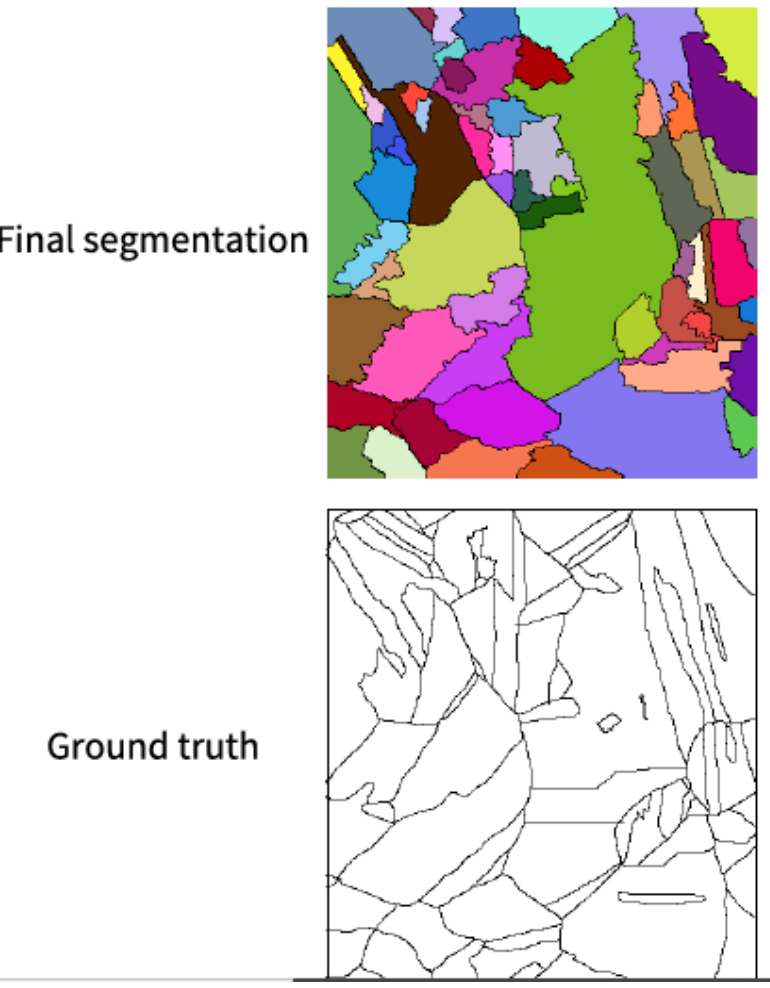

Test_02
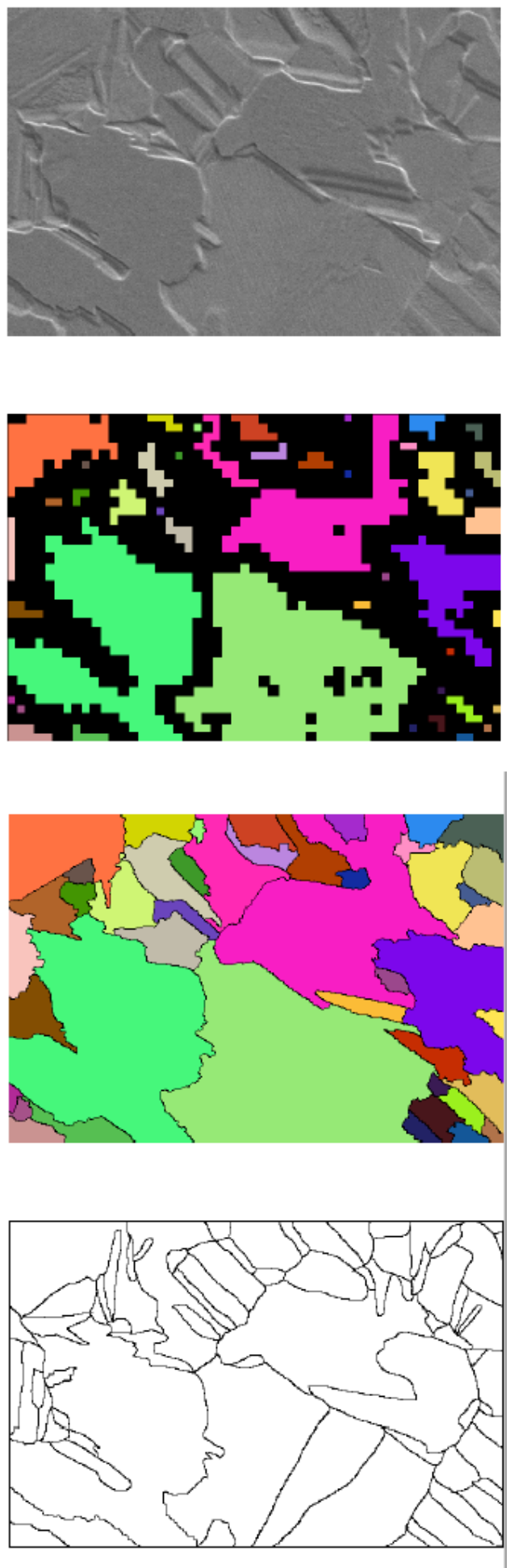

Figure 6

Results for SEM images. 